\title{
A EDUCAÇÃO AMBIENTAL COMO RESPOSTA AO CAOS SOCIOAMBIENTAL NO CONTEXTO DA SOCIEDADE DE RISCO
}

\author{
ENVIROMENTAL EDUCATION AS A RESPONSE TO CHAOS SOCIO- \\ ENVIRONMENTAL IN THE CONTEXT OF RISK SOCIETY
}

\author{
Dayla Barbosa Pinto ${ }^{1}$ \\ Danielle de Ouro Mamed $^{2}$
}

\section{RESUMO}

Com o desequilíbrio na relação homem-natureza instalou-se uma crise socioambiental, cuja própria humanidade passou a sofrer as consequências de suas investidas consumistas. Dentro desse contexto, a Educação Ambiental constitui valiosa ferramenta, capaz de libertar o homem da roda viva do consumismo e colocá-lo no eixo de sua própria existência outra vez. Assim, tal estudo busca demonstrar que o equilíbrio na relação homem-natureza e a gestão da crise socioambiental, deve partir, da (re) educação da humanidade quanto à modernidade e seus efeitos, adotando-se para isso a metodologia de pesquisa bibliográfica qualitativa, análise de doutrina e artigos científicos. Assim, utilizou-se o método exploratório do tema proposto, apontando a educação ambiental como mecanismo de resposta à desordem imposta no contexto da sociedade de risco.

Palavras-chave: Educação Ambiental; Direito Socioambiental; Sociedade de Risco.

\begin{abstract}
With the imbalance in the relation man-nature settled a social-environmental crisis, whose own humanity began to suffer the consequences of its consumerist onslaughts. Within this context, Environmental Education is a valuable tool, capable of freeing man from the living circle of consumerism and putting him on the axis of his own existence again. Thus, this study seeks to demonstrate that the equilibrium in the relationship between man and nature and the management of the socio-environmental crisis must start from the (re) education of humanity regarding modernity and its effects, adopting for this the methodology of qualitative bibliographical research, Analysis of doctrine and scientific articles. Thus, the exploratory method of the proposed theme was used, pointing to environmental education as a response mechanism to the disorder imposed in the context of the risk society.
\end{abstract}

Keywords: Environmental Education; Socio-Environmental; Risk Society.

\footnotetext{
${ }^{1}$ Mestranda em Direito Ambiental pela Universidade do Estado do Amazonas (UFAM). Pós-Graduanda em Psicopedagogia e Metodologia do Ensino Superior pelo Instituto Valor. Advogada. Amazonas (Brasil). E-mail: daylabp@gmail.com.

${ }^{2}$ Doutora em Direito Econômico e Socioambiental pela Pontifícia Universidade Católica do Paraná (PUCPR). Professora em Estágio Pós-Doutoral na Universidade do Contestado (UnC/SC). Santa Catarina (Brasil). E-mail: mamed.danielle@gmail.com.
} 


\section{INTRODUÇÃO}

O ser humano costumava manter íntima ligação com a natureza, entretanto, essa relação pouco a pouco foi sendo modificada, dando lugar a uma nova forma de interação, mercantilizada e mecânica. A natureza, então, passou a servir ao homem não somente em medida suficiente para sua subsistência, mas, com extrema submissão aos interesses econômicos do mesmo. Na verdade, as diversas mudanças ocorridas no contexto social especialmente da pós-modernidade -, modificaram também a relação homem-natureza, ensejando em uma apressada e irresponsável degradação dos recursos naturais, fato este que tem trazido severas consequências à própria humanidade.

Sabendo que a educação exerce papel fundamental na formação de ideias e direcionamento da conduta humana, entende-se que tal ferramenta pode ser especialmente útil para contornar a crise socioambiental já instalada. A educação ambiental pode, portanto, servir como instrumento para (re) educar a humanidade, fazendo-a perceber os necessários limites que devem ser respeitados no contexto da sociedade de risco, a fim de frear o ritmo acelerado do caos socioambiental.

Nesse sentido, buscando melhor compreensão do tema proposto, inicialmente optouse por tratar acerca do conceito de educação e sua origem histórica, mediante a investigação dos elementos que compõem o processo educativo bem-sucedido bem como, de que maneira tal sistema se consolidou no decorrer da história, salientando-se a importância da educação democrática para a formação do caráter do ser humano e, ainda, como meio de organização e controle social especificamente no âmbito ambiental.

Além disso, avaliou-se a abordagem dada pelo Professor Genebaldo Freire acerca da Educação Ambiental e os desdobramentos do processo educativo dentro dessa temática, ressaltando-se os pontos fortes expostos pelo doutrinador em conjunto com os outros posicionamentos doutrinários.

Ademais, foram delineados aspectos relevantes sobre a estrutura sob a qual se funda a sociedade pós-moderna, enfatizando-se suas principais características, sobretudo quanto ao consumismo exacerbado. Tal observação foi feita mormente em virtude da íntima ligação existente entre os padrões pós-modernos de consumo e produção e a consolidação da crise socioambiental, vez que esta última insinua-se como decorrente, em certa medida, de tais padrões.

A este respeito, fez-se uma singela análise acerca da interligação que pode ser feita entre a educação ambiental e a modernidade, realçando o entendimento de que ambos os 
fenômenos devem ser reconciliados a fim de conduzir o ser humano a uma melhor gestão de sua atual condição. Ainda nesse contexto, verificou-se a interferência da modernização e seus efeitos na crise socioambiental, identificando a educação ambiental como possível solução para tal crise.

Por fim, optou-se por analisar de que modo a educação ambiental pode servir ao propósito de responder ao caos socioambiental decorrente do ritmo da sociedade capitalista, sublinhando-se o papel essencial da educação nesse processo.

Por oportuno, importa mencionar a utilização do método exploratório e da técnica de pesquisa bibliográfica, para sincronização dos conceitos e da doutrina acerca da educação ambiental com a teoria da sociedade de risco, a fim de identificar a provável forma por meio da qual a educação ambiental pode ser utilizada como mecanismo de resposta à desordem imposta no contexto da sociedade de risco, longe da tentativa de esgotar o tema, mas, tão somente, para ampliar a discussão a respeito do referido conteúdo.

Assim, sabendo que a sociedade atual - sociedade de risco -, corre euforicamente em direção a um futuro cheio de incertezas e, ainda, considerando o fato de que se vê incontestável a existência de uma crise socioambiental de alcance global, a ponderação das questões levantadas no presente estudo se demonstra fundamental, vez que possibilitará reflexões sobre o rumo a ser tomado pela sociedade de consumo, bem como permitirá encontrar, na educação ambiental, a possível alternativa para desviar o planeta do assombroso caos para o qual ele se encaminha.

\section{BREVES COMENTÁRIOS ACERCA DO CONCEITO DE EDUCAÇÃO E SUA ORIGEM HISTÓRICA}

Primeiramente, faz-se essencial realizar uma abordagem histórica e conceitual acerca da educação, a fim de que obter melhor compreensão acerca de tal fenômeno, bem como para compreender de que modo a educação pode ser utilizada como mecanismo de reorganização social no contexto ambiental.

Conforme White, em seus livros Educação e Conselhos sobre Educação, a educação verdadeira consiste no desenvolvimento harmônico das faculdades físicas, intelectuais e mentais. Segundo ela, a devida educação colabora para o desenvolvimento da moral, bem como, do comportamento correto. Dessa forma, "a devida educação inclui, não somente a disciplina mental, mas aquele cultivo que garante a moral reta e correto comportamento" 
(WHITE, p. 62, 2008). Nesse contexto, a educação não estaria somente ligada à aplicação de técnicas para a transmissão de determinados conhecimentos, mas, à formação de caráter e ampliação do alcance da mente.

Já Maria Lúcia de Arruda Aranha, tratando acerca do conceito de educação, sabiamente afirma que "A educação não é, porém, a simples transmissão da herança dos antepassados, mas o processo pelo qual também se torna possível a gestação do novo e a ruptura com o velho" (ARANHA, p. 50, 1996).

Além disso, a autora ainda defende que "Educação é um conceito genérico, mais amplo, que supõe o processo de desenvolvimento integral do homem, isto é, de sua capacidade física, intelectual e moral, visando não só a formação de habilidades, mas também do caráter e da personalidade social” (ARANHA, p. 51, 1996).

Nesse sentido, pode-se dizer que a educação corresponde ao processo ao qual o sujeito está submetido durante o período de construção de sua autonomia individual e apreensão de novos conhecimentos acerca de si mesmo e do coletivo à sua volta.

Tratando acerca da história da educação, a Professora Maria Lúcia Aranha ensina que a educação se constrói no desenrolar da história geral. Ela (a educação) está intimamente ligada ao desenvolvimento da própria história e com ela se confunde. Ainda a este respeito, a doutrinadora discorre sobre o avanço da educação no decorrer do cenário histórico, enfatizando que na Grécia clássica - século $\mathrm{V}$ a.C -, um percentual muito pequeno era considerado cidadão livre e, portanto, tinha acesso à educação.

Considerando este dado, entende-se que somente uns poucos tinham acesso à educação, sendo, consequentemente, a educação, um privilégio de poucos ou dos ricos daquele período histórico. Além disso, no período da Antiguidade romana fora oficializado o ensino, ocasião em que o Estado assume o encargo da educação (ARANHA, p. 79, 1996).

Posteriormente, no período da Idade Média, registra-se o desaparecimento das escolas, isso porque tem-se o momento da formação dos reinos bárbaros. Pode-se afirmar, portanto, que a Idade Média foi o período histórico no qual a educação foi pouco difundida, sendo retomada somente no período do Renascimento. É nesse último período que surge uma "proposta de implantação de instrução universal", por meio da qual a educação passaria a ser uma obrigação do Estado (ARANHA, p. 79, 1996).

Assim, nota-se que por mais que a educação tenha ficado certo período de tempo em uma espécie de "esquecimento", ela sempre esteve presente, ainda que indiretamente nos processos de interação cultural, vez que se encontra atrelada à própria construção do processo histórico. 


\title{
2 A EDUCAÇÃO COMO DIREITO FUNDAMENTAL
}

As disposições, quanto à educação, encontradas nos ordenamentos jurídicos visam orientar a implementação de uma educação de qualidade capaz de oferecer técnicas e valores que habilitem os seres humanos e os tornem capazes de viver plenamente em sociedade, exercendo seus deveres civis e políticos e gozando de seus direitos.

O entender da lei é que a educação deve preparar o ser humano para o pleno convívio social e desenvolvimento de suas faculdades mentais. Neste sentido, a educação deve tornar o homem independente, capaz de dirimir conflitos e ser útil à sociedade.

Vale ressaltar, ainda, o que dispõem a Declaração Universal dos Direitos Humanos, em seu art. $26, \S \S 1^{\circ}$ e $2^{\circ}$, quando trata do direito de todos à educação, conforme se verifica a seguir:

\author{
Artigo 26 \\ $\S 1^{\circ}$ - Toda pessoa tem direito à instrução $[\ldots]$ \\ $\S 2^{\circ}$ - A instrução será orientada no sentido do pleno desenvolvimento da \\ personalidade humana e do fortalecimento do respeito pelos direitos humanos e \\ pelas liberdades fundamentais. A instrução promoverá a compreensão, a tolerância e \\ a amizade entre todas as nações e grupos raciais ou religiosos [...].
}

E, ainda, o que dispõe o Pacto Internacional sobre Direitos Econômicos, Sociais e Culturais, em seu art. 13 e o Protocolo de San Salvador, também no art. 13, respectivamente, quais sejam:

\begin{abstract}
Artigo 13
1. Os Estados Partes do presente Pacto reconhecem o direito de toda pessoa à educação. Concordam em que a educação deverá visar ao pleno desenvolvimento da personalidade humana e do sentido de sua dignidade e fortalecer o respeito pelos direitos humanos e liberdades fundamentais. Concordam ainda em que a educação deverá capacitar todas as pessoas a participar efetivamente de uma sociedade livre, favorecer a compreensão, a tolerância e a amizade entre todas as nações e entre todos os grupos raciais, étnicos ou religiosos e promover as atividades das Nações Unidas em prol da manutenção da paz.
\end{abstract}

\section{Artigo 13}

1. Toda pessoa tem direito à educação.

2. Os Estados-Partes neste Protocolo convêm em que a educação deverá orientar-se para o pleno desenvolvimento da personalidade humana e do sentido de sua dignidade e deverá fortalecer o respeito pelos direitos humanos, pelo pluralismo ideológico, pelas liberdades fundamentais, pela justiça e pela paz. Convêm, também, em que a educação deve capacitar todas as pessoas para participar efetivamente de 
uma sociedade democrática e pluralista, conseguir uma subsistência digna, favorecer a compreensão, a tolerância e a amizade entre todas as nações e entre todos os grupos raciais, étnicos ou religiosos e promover as atividades em prol da manutenção da paz.

O que se percebe da avaliação dos dispositivos legais supracitados é que a preocupação implícita nos ordenamentos jurídicos não é a de simplesmente oferecer acesso à educação, mas, possibilitar a formação e o desenvolvimento pleno do indivíduo, de forma que este seja capaz de construir o saber por meio de sua vivência. Neste sentido, os dispositivos legais apontados visam resguardar a efetivação de uma educação de qualidade, que permita o crescimento técnico, mas, sobretudo, humano.

Na verdade, o que a lei defende quando prediz “[...] a educação deverá orientar-se para o pleno desenvolvimento da personalidade humana $[. .$.$] ”, que a educação “[...] deverá$ fortalecer o respeito pelos direitos humanos, pelo pluralismo ideológico, pelas liberdades fundamentais, pela justiça e pela paz [...]", ou, ainda, quando afirma que "[...] a educação deve capacitar todas as pessoas para participar efetivamente de uma sociedade democrática e pluralista [...]", é exatamente a filosofia apregoada e defendida por modelos de educação mais modernos.

Assim, é nítido o vínculo existente entre as disposições legais a respeito da educação e a filosofia defendida por modelos educacionais mais modernos e democráticos, que, pela interpretação das normas apresentadas, encontram-se em perfeita concordância com o ordenamento jurídico vigente. Sendo assim, pode-se afirmar, que as leis supracitadas preveem o direito fundamental à educação, buscando a formação completa e dinâmica do indivíduo, preparando-o para aos desafios do 'viver em sociedade'.

\section{A EDUCAÇÃO AMBIENTAL NA VISÃO DE GENEBALDO FREIRE}

A educação ambiental por muitos anos apresentou-se tímida no cenário nacional e internacional. Na verdade, em países como o Brasil, onde a educação ambiental seria mais necessária por conta do contexto socioeconômico, acabou-se não tendo o crescimento esperado inicialmente.

É válido frisar que segundo o professor Genebaldo Freire o conceito de Educação Ambiental surgiu em 1970, por meio da IUCN, e consiste em em "processo de reconhecimento de valores e de esclarecimentos de conceitos, que permitam o desenvolvimento de habilidades e atitudes necessárias para entender e apreciar as inter- 
relações entre o homem, sua cultura e seu ambiente biofísico circunjacente" (DIAS, p. 29, 2000).

Importante mencionar que o referido doutrinador cita a Conferência das Nações Unidas sobre Meio Ambiente e Desenvolvimento - de julho de 1991 -, como importante para o lançamento das bases conceituais de educação ambiental, afirmando o seguinte:

\begin{abstract}
A educação ambiental se caracteriza por incorporar as dimensões sócio-econômica, política, cultural e histórica, não podendo basear-se em pautas rígidas e de aplicação universal, devendo considerar as condições e estágio de cada país, região e comunidade, sob uma perspectiva histórica. Assim sendo, a educação ambiental deve permitir a compreensão da natureza complexa do meio ambiente e interpretar a interdependência entre os diversos elementos que conformam o ambiente, com vistas a utilizar racionalmente os recursos do meio na satisfação material $e$ espiritual da sociedade no presente e no futuro. (DIAS, p. 31, 2000)
\end{abstract}

O fato é que para a efetivação da educação ambiental faz-se mister, no entendimento do referido doutrinador, observar a correta compreensão da natureza, bem como fazer a adequada interpretação acerca da interdependência "entre os diversos elementos que conformam o ambiente". Importante lembrar que segundo defendido pelo ilustre professor, a educação ambiental de certo modo adequa-se à realidade local, posto que não pode basear-se em "pautas rígidas e de aplicação universal".

Diante disso, pressupõe-se que a educação ambiental somente pode ser efetivada se estruturada em um formato dinâmico e democrático, capaz de fornecer os subsídios necessários para que o sujeito desenvolva as respectivas competências para lidar com questões ambientais de sua localidade, o que remete inclusive ao conceito de "escolademocrática" defendido por Josep M. Puig (2000).

No que se refere ao modelo de educação "escola cidadã", pode-se afirmar que os princípios do mesmo definem não apenas sua estruturação e seu direcionamento, mas, externam a filosofia de sua existência, bem como os valores sobre os quais se funda. Sendo assim, a análise e avaliação crítica e multidisciplinar se faz mister visto possibilitar melhor e completa compreensão da escola cidadã ou escola democrática.

A este respeito, frise-se que no método defendido pela escola cidadã, cada indivíduo é sujeito do conhecimento e, portanto, pode, a partir de sua própria vivência, gerar novos conhecimentos. A escola cidadã busca, ainda, a humanização e preservação dos direitos sociais de igualdade, liberdade, educação, etc., que definem o homem enquanto ser social e ainda, possibilitam seu pleno desenvolvimento, o que se apresenta como similar àquilo pretendido pela educação ambiental, ou melhor dizendo, com a metodologia por ela utilizada. 
Ademais, Genebaldo Freire defende que a educação ambiental, para ser transformadora deve capacitar o aluno para o exercício da cidadania, ou seja, "a educação ambiental deve capacitar ao pleno exercício da cidadania, através da formação de uma base conceitual abrangente, técnica e culturalmente capaz de permitir a superação dos obstáculos à utilização sustentada do meio" (DIAS, p. 31, 2000).

Neste contexto, quando se define como princípio uma ordem que verse sobre o respeito às características peculiares dos indivíduos, bem como a elaboração de métodos que permitam a inclusão dos mesmos, se está buscando a entronização de valores sociais de forma a permitir que estes norteiem a atividade educacional como um todo.

$\mathrm{Na}$ verdade, se defende a filosofia de uma "pedagogia liberal", no sentido de permitir a prevalência dos interesses e liberdades de cada indivíduo e, ainda, no sentido de respeitar a autonomia do educando, conforme defende Paulo Freire, pois, "O respeito à autonomia e à dignidade de cada um é um imperativo ético e não um favor que podemos ou não conceder uns aos outros" (FREIRE, p. 59, 1996).

Além disso, o próprio professor Genebaldo afirma que "Um programa de EA, para ser efetivo, deve promover, simultaneamente, o desenvolvimento de conhecimento, de atitudes e de habilidades necessárias à preservação e melhoria da qualidade ambiental" (DIAS, p. 116, 2000). Ora, o ponto principal da proposta da EA é justamente a ação! São as atitudes do indivíduo, como parte ativa no processo educativo, que despertarão suas habilidades e desenvolverão melhorias para a localidade na qual o mesmo estiver inserido.

Assim, atualmente, não se pode conceber a ideia de uma educação una e estática que não seja flexível às diversas realidades locais, sobretudo no âmbito do direito ambiental. Deve-se primar, portanto, por métodos e iniciativas democráticos, respeitando-se as peculiaridades de cada localidade, que não conserva uniformidade, mas que está em constante transformação.

\section{A SOCIEDADE DE CONSUMO E OS EFEITOS DA MODERNIDADE NA RELAÇÃO HOMEM-NATUREZA}

A teoria de Ulrich Beck aponta para uma configuração social baseada no risco e nos efeitos colaterais decorrentes da modernização, que geram ameaças à vida da humanidade e da natureza (BECK, 2010, p. 16). Esse espantoso modelo social da modernidade, ao mesmo tempo em que permitiu conquistas significativas no campo da indústria, ciência e tecnologia, também trouxe consigo uma tendência rumo a estágios extremos na produção de riscos e 
ameaças, ensejando na constante expectativa de acidentes em escala mundial, capazes de provocar até mesmo o extermínio da vida no planeta.

A respeito da modernidade Aranha afirma, ainda, que "os prejuízos na qualidade de vida propriamente humana são fruto das contradições insolúveis do sistema engendrado na modernidade" (ARANHA, 1996, p. 237). Na verdade, nota-se existir uma crise que ameaça a humanidade e que decorre especialmente da atuação do próprio ser humano na natureza. De um lado, a modernidade trouxe inovações espetaculares e nunca antes imaginadas, na área da ciência e tecnologia especialmente, entretanto, juntamente com isso, impôs um ritmo frenético que conduz o ser humano à destruição da natureza e produz graves consequências ambientais:

\begin{abstract}
O contraponto do progresso se encontra na ameaça nuclear e na degradação ambiental com os perigos da poluição industrial, desertificação, destruição da flora e da fauna, efeito estufa, buraco na camada de ozônio. São exemplos do que os filósofos frankfurtianos chamam de sofrimento da natureza, infligido pelo homem, incapaz de reconhecer que a natureza não é uma realidade a ser dominada. Não por acaso, segundo Horkheimer, "a história dos esforços humanos para subjugar a natureza é também a história da subjugação do homem pelo homem" (ARANHA, 1996, p. 237).
\end{abstract}

De igual modo, Leonardo Boff entende que "A realidade é que o ser humano faz parte do meio ambiente. Ele é um ser da natureza, com capacidade de modificar a si mesmo e a ela, e assim fazer cultura. Pode intervir na natureza potenciando-a, bem como agredindo-a" (BOFF, 2009, p. 132). Quanto a isto, faz-se indispensável mencionar também o entendimento de Ulrich Bech, a saber:

\footnotetext{
A oposição entre natureza e sociedade é uma construção do século XIX, que serve ao duplo propósito de controlar e ignorar a natureza. A natureza foi subjugada e explorada no final do século XX e, assim, transformada de fenômeno predeterminado em fabricado. Ao longo de sua transformação tecnológico-industrial e de sua comercialização global, a natureza foi absorvida pelo sistema industrial. Dessa forma, ela se converteu, ao mesmo tempo, em pré-requisito indispensável do modo de vida no sistema industrial. (BECK, 2010, p. 9).
}

Certamente, a modernidade permitiu ao ser humano a modificação rápida da natureza, por meio da indústria e consequentemente dos processos produtivos acelerados, restando instaurada uma verdadeira crise socioambiental. Vê-se, portanto, que o cerne da questão se encontra no fato de que a atuação do ser humano para modificar o meio ambiente deixou de ocorrer de modo artesanal e tornou-se industrializada, com produção acelerada e em grande escala. 
$\mathrm{Na}$ verdade, como afirma Marx, essa necessidade do ser humano, de "controlar socialmente uma força natural, de administrá-la, começando por apropriá-la ou dominá-la" exerceu um "papel decisivo na história da indústria" (MARX, 2015, p. 142) - e porque não dizer da própria natureza? Pode-se afirmar, portanto, que na atualidade o homem goza de mais ferramentas de exploração da natureza e estas encontram-se potencialmente mais perigosas e com maior alcance.

Nesse enredo, Mamed aponta algumas das consequências ambientais decorrentes da modernização, expressas na modificação da relação homem-natureza e na produção demasiada de bens de consumo, a saber, "o crescimento do consumo" e proporcionalmente a necessidade de exploração crescente dos recursos naturais disponíveis, e, ainda, a "maior produção de resíduos", que obviamente não podem ser absorvidos na mesma velocidade com que são produzidos, gerando com isso "os passivos de poluição do meio ambiente" (MAMED, 2015, p. 3).

Além disso, é possível apontar outros problemas trazidos pela modernização revelados nos problemas sociais, políticos e ambientais que assolam a sociedade atual, tanto que Ulrich Beck identifica a existência de uma verdadeira "crise institucional” no núcleo da própria sociedade industrial (BECK, 1997, p. 19), bem como Maria Lúcia de Arruda Aranha reconhece tal situação, afirmando que atualmente se vive "a crise do paradigma da modernidade" (ARANHA, 1996, p. 236).

De fato, percebe-se existir uma crise da modernidade, crise esta revelada por meio das ameaças e riscos produzidos pelo modo de vida do ser humano e da exploração desmedida dos recursos naturais. De certo modo, nota-se que atualmente tornou-se possível ao homem a degradação do meio ambiente pelos mais diversificados meios, ocasionando um verdadeiro colapso socioambiental, que não pode ser gerido, vez que está enraizado na própria proposta da sociedade moderna, pois, conforme constatado por Beck, a natureza tornou-se um produto da sociedade pós-industrial (BECK, 1997, p. 40), e tal fato evidencia-se justamente pela mudança na interação homem-natureza. Em divergência ao que entende a filosofia propagada pela modernidade - da natureza vista como um produto -, tem-se a oportuna reflexão trazida por Ricardo Jiménez, segundo o qual:

Diferentemente do pensamento ocidental moderno, não se trata de um mundo, uma natureza e um meio ambiente "objeto" com o qual o sujeito humano se relaciona, senão de um mundo que é em si mesmo sujeito, mais claramente, ser vivo, pessoa, e onde tudo o que o integra é por sua vez sujeito, ser vivo e pessoa, inclusive os solos, as águas, as pedras, os montes, as neblinas, as chuvas, os astros, os antepassados, as huacas -seres espirituais-, e por suposto os seres humanos, os animais e as plantas. (JIMÉNEZ, 2011, p. 9) 
Na verdade, o problema da modernidade parece consistir no fato de que ela traz em si "padrões, esperança e culpa" incoerentes, pois, impele o ser humano a tentar, num ritmo frenético, alcançar padrões aparentemente inatingíveis, conforme assevera Bauman (BAUMAN, 1998, p. 91). Na facilitação da busca por alternativas para resolução dessa problemática, Aranha defende que:

\begin{abstract}
Se vivemos hoje o mal-estar da modernidade, em decorrência das promessas abortadas da racionalidade expressa na ciência, na técnica, na ilusão do progresso, à qual se contrapõem de maneira cruel duas guerras mundiais, Auschwitz, Hiroshima, o desequilíbrio ecológico e a ameaça de aniquilação atômica, não há por que se refugiar no irracionalismo. Por isso, contestar a modernidade não significa necessariamente recusá-la, mas sim repensá-la [...] Mais do que sucumbir à desrazão, cumpre denunciar os desvios da razão enlouquecida. (ARANHA, 1996, 229).
\end{abstract}

Igualmente, destaca-se o pensamento de Cristiane Derani, segundo a qual a proteção do meio ambiente só pode ser considerada em uma sociedade na qual se "desenvolve a relação homem-natureza", de maneira que a necessária "construção de uma política de conservação das bases naturais devem ser buscados e encontrados no interior da sociedade industrial-tecnológica moderna, reformulando seus pressupostos, num processo de conscientização”. (DERANI, 2003, p. 66).

Neste sentido, Aranha e Derani parecem indicar que a crise socioambiental e os problemas advindos da modernidade somente podem ser resolvidos - ou ao menos pode-se tentar resolvê-los -, mantendo-se uma postura reflexiva, com a consequente reformulação dos próprios fundamentos da sociedade moderna por meio de um "processo de conscientização", que permita a reconfiguração dos meios de produção atualmente adotados pela sociedade industrial.

Assim, percebe-se que a conduta mais adequada para o enfrentamento da crise socioambiental - que, na verdade, decorre de uma crise institucional ocorrida no núcleo da própria modernidade -, é justamente a reconsideração dos fundamentos da modernidade e, consequentemente, do modo como o ser humano tem se relacionado com a natureza. É nítido o desgaste oriundo da exagerada exploração do meio ambiente e mais nítido ainda o fato de que tal degradação ambiental advém do ritmo de vida imposto pela modernidade, por isso, pensar a modernidade em si e seus desdobramentos pode significar um passo para mais perto da resolução desta problemática. 


\title{
5 A EDUCAÇÃO AMBIENTAL COMO RESPOSTA AO CAOS SOCIOAMBIENTAL
}

Considerando o enredo apresentado, nota-se que a educação ambiental tem caráter libertador e pode funcionar como mecanismo de resposta ao caos socioambiental instalado na sociedade pós-moderna, isso porque o primeiro passo para a resolução das questões ambientais, certamente é a mudança de perspectiva, de comportamento, do indivíduo e isso se dá por meio da educação.

Ao se referir a determinado tipo de estratégia adotada na educação ambiental - a estratégia de "resoluções de problemas" -, o professor Genebaldo Freire justifica sua escolha:

\begin{abstract}
A escolha dessa estratégia se justifica, porque ela é capaz de: ajudar os alunos na compreensão do metabolismo urbano, e levá-los a ações que possam influenciar nesse metabolismo; estimular a formação de uma mentalidade que os levem a se envolver na identificação e resolução dos problemas da sua comunidade (permite a redução dos sentimentos de frustração - a "síndrome da angústia ambiental" -, despersonalização e anonimato frequentemente experimentados pela população urbana); ajudar os alunos a desenvolver atividades que busquem soluções dos problemas ambientais atuais e projetados, da sua cidade. (DIAS, p. 117, 2000).
\end{abstract}

Sob essa ótica, vê-se que o processo educativo pode ser utilizado como instrumento de conscientização do indivíduo que se encontra inserido na sociedade e, consequentemente pode possibilitar um despertar desse indivíduo para as questões ambientais. Na verdade, notase que a própria educação ambiental se propõe a ser dinâmica e promover transformações no contexto social.

A este respeito, deve-se mencionar que o tipo de abordagem da educação ambiental sugere a participação popular e a (re) educação das comunidades para as necessidades daquela localidade, dando ao indivíduo a consciência de que o mesmo pode realizar as mudanças adequadas para transformar o meio em que vive.

Dessa forma, torna-se inevitável concluir que a educação ambiental, sob a ótica dos princípios apresentados, deve ser ampla, transformadora, prática, realista, comprometida e dinâmica. Deve respeitar as peculiaridades dos diversos grupos sociais e das comunidades. Deve respeitar as distintas realidades, valorizando o que cada uma pode oferecer.

Considerando as ponderações apresentadas, nota-se que a educação ambiental deve se preocupar com a formação política e crítica de seus alunos e, portanto, deve ser ativa na comunidade na qual estiver inserida. A educação ambiental deve, portanto, conservar a unidade (no que diz respeito à execução de suas atividades e preservação de sua filosofia), todavia, deve respeitar a diversidade, fazendo uso da mesma na formação e realização de um ensino mais dinâmico e conscientizador. 
Assim, os princípios da educação ambiental buscam, em suma, a efetivação da função social do ensino e da educação no contexto ambiental. Os parâmetros adotados pela educação ambiental coroam, ainda, a necessidade de respeito aos valores que são fundamentais ao homem enquanto sujeito social.

Destaca-se, ainda, o que afirma White, em sua obra Conselhos sobre educação (2008, p. 47), a saber: "A educação compreende mais que conhecimentos de livros. A devida educação inclui, não somente a disciplina mental, mas aquele cultivo que garante moral reta e correto comportamento". Neste sentido, pode-se afirmar que não apenas deve-se preparar a mente dos alunos para a acumulação de conhecimento, mas preocupar-se com o pleno e sério desenvolvimento moral e político dos mesmos, inclusive mediante o exercício da cidadania no âmbito da preservação ambiental.

O fato é que a educação ambiental deve visar o processo educativo de modo a não permitir que o aluno seja apenas receptor de conhecimento, mas, transformador da sua realidade.

Ainda neste sentido, sabiamente se manifesta Hengemühle (2008, p. 58), ao afirmar que "Hoje uma educação de qualidade significa oferecer instrumentos para que os indivíduos possam desenvolver-se e ampliar sua autonomia, que tenham capacidade de autodirigir-se, de pensar com a própria cabeça, fazer escolhas e responsabilizar-se por elas”. Em outras palavras, a verdadeira educação molda o indivíduo para que ele tenha autonomia e instrumentos suficientes para dirimir conflitos.

Partindo desse pressuposto, pode-se afirmar que a educação ambiental se apresenta como um instrumento peculiar de transformação do contexto social, bem como tem em vista a formação dinâmica e multidisciplinar dos indivíduos vez que promove a reflexão, a postura dinâmica e participativa, razão pela qual pode funcionar em resposta à desordem decorrente do contexto da sociedade de consumo.

\section{CONSIDERAÇÕES FINAIS}

Certamente, muitos são os desafios a serem enfrentados para a implementação da educação ambiental. Desde a falta de estrutura física ao despreparo técnico de muitos “educadores", podem ser apontados como empecilhos ao implemento desta filosofia de educação. Entretanto, não é mais possível contentar-se com um modelo de educação que ignore as questões ambientais e suas problemáticas. É preciso que a educação atenda sua 
função social que é, justamente, formar cidadãos conscientes, especialmente diante dos problemas socioambientais.

Neste sentido, restou claro que a educação ambiental, por meio de métodos dinâmicos e democráticos, pode ser valioso instrumento na persecução de transformações no contexto da sociedade de consumo, sobretudo quanto a preservação do meio ambiente por parte da sociedade.

Assim, entende-se que é este pensamento que deve balizar o ato de ensinar, bem como é essa ideologia que deve funcionar como mola propulsora na busca por uma educação ambiental transformadora, rompendo com o método de ensino-aprendizagem vigente e possibilitando um novo conceito, mais amplo e dinâmico, capaz de oferecer respostas efetivas para os problemas socioambientais existentes no contexto da sociedade de consumo.

\section{REFERÊNCIAS}

ARANHA, Maria Lúcia de Arruda. Filosofia da educação. $2^{\text {a }}$ ed. rev. e ampl. São Paulo: Moderna, 1996.

História da educação. $2^{a}$ ed. rev. atual. São Paulo: Moderna, 1996.

BAUMAN, Zygmunt. O mal-estar da pós-modernidade. Tradução de Mauro Gama. Rio de Janeiro: Jorge Zahar Ed., 1998.

BECK, Ulrich; GIDDENS, Anthony; LASH, Scott. Modernização reflexiva: política, tradição e estética na ordem social moderna. Tradução de Magda Lopes. São Paulo: Editora Unesp, 1997.

Sociedade de risco. Tradução de Sebastião Nascimento. São Paulo: Ed. 34, 2010.

Ética da vida: a nova centralidade. Rio de Janeiro: Record, 2009.

DERANI, Cristiane. Tutela jurídica da apropriação do meio ambiente e as três dimensões da propriedade. Hiléia: Revista de Direito Ambiental da Amazônia, Manaus, ano 1, n. 1, p 65- 88, jan 2003.

DIAS, G. F. Educação Ambiental: princípios e práticas. 6. ed. São Paulo: Gaia, 2000.

FREIRE, Paulo. Pedagogia da Autonomia: saberes necessários à prática educativa. São Paulo: Paz e Terra, 1996.

HENGEMÜHLE, Adelar. Gestão de ensino e práticas pedagógicas. 5. Ed. Petrópolis, RJ: Vozes, 2008.

JIMÉNEZ, Ricardo. Resgatar e valorizar outros pilares éticos: o Bom Viver. In: Conferência Rio+20 - Ateliê Internacional: Biocivilização. Rio de Janeiro, 2011. 
LEITE, José Rubens Morato; AYALA, Patryck de Araújo. Dano ambiental: do individual ao coletivo extrapatrimonial. 4ª . Ed. São Paulo: Revista dos Tribunais, 2011.

MAMED, Danielle de Ouro; LIMA, Cyntia Costa de. Modernidade e mercantilização da natureza: o ataque aos bens comuns pelos Pagamentos de Serviços Ambientais. In: ANAIS DO IX CONGRESSO DA REDE LATINOAMERICANA DE ANTROPOLOGIA JURÍDICA: SOCIEDADES PLURAIS E ESTADOS NACIONAIS: LIMITES E DESAFIOS PARA A EFETIVIDADE DE DIREITOS. Pirenópolis: UFG - UnB - PUC PR, 2015.

MARX, Karl Heinrich. O capital. Disponível em: <http://www.histedbr.fe.unicamp.br/acer_fontes/acer_marx/ocapital-2.pdf> Acesso em: 16 de out. 2015.

SIRVINSKAS, Luis Paulo (Org.). Legislação de direito ambiental. 4. ed. São Paulo: Rideel, 2009.

PUIG, Josep M [et al.]. Democracia e participação escolar: propostas de atividades. Tradução: Maria Cristina de Oliveira. São Paulo: Moderna, 2000.

WHITE, Ellen G. Conselhos sobre educação: lições de um sistema de ensino bemsucedido. Tradução de Carlos A. Trezza. Tatuí, SP: Casa Publicadora Brasileira, 2008.

WHITE, Ellen G. Educação: um modelo de ensino integral. Tradução de Flávio Lopes Monteiro. Tatuí, SP: Casa Publicadora Brasileira, 2008. 